\title{
Artificial rearing influences the morphology, permeability and redox state of the gastrointestinal tract of low and normal birth weight piglets
}

\author{
Hans Vergauwen ${ }^{1 \dagger}$, Jeroen Degroote ${ }^{2 \dagger}$, Sara Prims ${ }^{1}$, Wei Wang ${ }^{2,3}$, Erik Fransen ${ }^{4}$, Stefaan De Smet ${ }^{3}$,
} Christophe Casteleyn ${ }^{1}$, Steven Van Cruchten ${ }^{1}$, Joris Michiels ${ }^{2}$ and Chris Van Ginneken ${ }^{1 *}$

\begin{abstract}
Background: In this study the physiological implications of artificial rearing were investigated. Low (LBW) and normal birth weight (NBW) piglets were compared as they might react differently to stressors caused by artificial rearing. In total, 42 pairs of LBW and NBW piglets from 16 litters suckled the sow until d19 of age or were artificially reared starting at $\mathrm{d} 3 \mathrm{until} \mathrm{d} 19$ of age. Blood and tissue samples that were collected after euthanasia at 0, 3, 5, 8 and $19 \mathrm{~d}$ of age. Histology, ELISA, and Ussing chamber analysis were used to study proximal and distal small intestine histomorphology, proliferation, apoptosis, tight junction protein expression, and permeability. Furthermore, small intestine, liver and systemic redox parameters (GSH, GSSG, GSH-Px and MDA) were investigated using HPLC.

Results: LBW and NBW artificially reared piglets weighed respectively 40 and 33\% more than LBW and NBW sowreared piglets at $\mathrm{d} 19(P<0.01)$. Transferring piglets to a nursery at $\mathrm{d} 3$ resulted in villus atrophy, increased intestinal FD-4 and HRP permeability and elevated GSSG/GSH ratio in the distal small intestine at $\mathrm{d} 5(P<0.05)$. GSH concentrations in the proximal small intestine remained stable, while they decreased in the liver $(P<0.05)$. From d5 until d19, villus width and crypt depth increased, whereas PCNA, caspase-3, occludin and claudin-3 protein expressions were reduced. GSH, GSSG and permeability recovered in artificially reared piglets $(P<0.05)$.

Conclusion: The results suggest that artificial rearing altered the morphology, permeability and redox state without compromising piglet performance. The observed effects were not depending on birth weight.
\end{abstract}

Keywords: Milk replacer, Oxidative stress, Small intestine, Suckling period, Tight junction proteins

\section{Background}

The neonatal period in the pig's life is accompanied with high morbidity and mortality $[1,2]$. In addition, increasing litter sizes in modern swine production have led to higher rates of piglets born with a low birth weight (LBW) [3]. Both newborn LBW human [4-6] and LBW piglets [7-10] seem to have a lower capacity to mount an antioxidant response. Newborns transitioning from

\footnotetext{
* Correspondence: chris.vanginneken@uantwerpen.be

${ }^{\dagger}$ Equal contributors

${ }^{1}$ Laboratory of Applied Veterinary Morphology, Department of Veterinary

Sciences, Faculty of Biomedical, Pharmaceutical and Veterinary Sciences,

University of Antwerp, Campus Drie Eiken, Universiteitsplein 1, D.U.015, 2610

Wilrijk, Belgium

Full list of author information is available at the end of the article
}

maternal mediated respiration to autonomous pulmonary respiration outside the uterus are suddenly exposed to $\mathrm{O}_{2}$-derived free radicals [11]. This increased the production of reactive species in various organs [7]. A redox imbalance affects cellular signaling, protein synthesis, and enhances proteolysis that can ultimately lead to a dysfunctional intestinal barrier and suboptimal regenerative potential as shown in vitro [12-15]. Consequently, the observed redox imbalance and the downstream effects could explain the abnormal absorption and metabolism of nutrients, reduced growth and impaired development of the small intestine, liver, and muscle observed in LBW piglets [10, 16-21]. This redox imbalance appears to persist beyond weaning [9]. Wang et al. 
observed that mRNA expression of occludin, heme oxygenase 1, catalase, thioredoxin reductase genes and occludin protein expression continued to be lower in LBW pigs during the suckling period [21]. This apparently conflicts with the observation that LBW piglets that survive the critical first days after birth show an intestinal morphology, digestive capacity, cytokine production, intestinal motility and permeability that is comparable with those seen in normal birth weight (NBW) littermates [22-24].

The increasing incidence of supernumerary and LBW piglets has raised an urgent need for innovative rearing strategies [1]. Next to cross-fostering [25], supplementing piglets [26] and split nursing [27], piglets can be transferred to a nursery and artificially reared [28-30]. Similar to conventional weaning, the artificially reared piglet encounters psychological and physical stressors including maternal and littermate separation, abrupt changes in diet composition and environment, lower intake of bioactive substances, as well as unfamiliar drinking nipples, increased exposure to pathogens and antigens, comingling and establishment of social hierarchy with unfamiliar pigs from different litters. The physiological responses to the strategy of full artificial rearing are largely unknown. Conventional weaning is associated with the induction of intestinal oxidative stress [31-33] and LBW piglets have more difficulties to maintain a balanced redox state when exposed to weaning stressors [9]. It is unknown at present if the response to artificial rearing, since it includes similar stressors as conventional weaning, is different in LBW piglets-which have a lower antioxidant capacity [21]-compared to NBW piglets.

Therefore, we aimed to investigate the impact of artificial rearing on piglet performance, proximal and distal small intestinal (SI) morphology, mitosis, apoptosis, and tight junction protein expression, permeability, and SI, liver and systemic redox state development compared to conventional rearing. Given the similarities between conventional weaning stressors and artificial rearing stressors we hypothesized that artificial rearing results in a redox imbalance and negatively affects intestinal morphology and functionality. Secondly, given the differences observed between NBW and LBW piglets during the suckling period, we hypothesized that in view of their affected redox state, the morphology and functionality of the small intestine is suboptimal in LBW piglets and that artificial rearing has a greater negative impact in this birth weight category.

\section{Methods}

Pig model and tissue collection

Eighty-four piglets (Topigs hybrid $\times$ Piétrain) were selected during two consecutive farrowing rounds. Only sows with 14 or more live-born piglets were selected and no cross-fostered piglets were included in the experiment. Piglets were tagged and weighed within $12 \mathrm{~h}$ after parturition. A LBW piglet was defined as a pig having a birth weight between 0.75 and $0.90 \mathrm{~kg}$ and belonging to the lower quartile of litter birth weights. A NBW piglet had a birth weight within 1 SD unit of the mean birth weight of the whole litter. The average birth weight of all the piglets used in this study was $0.81 \pm 0.01 \mathrm{~kg}$ and $1.26 \pm 0.02 \mathrm{~kg}$ for LBW and NBW piglets, respectively. Forty-two pairs of LBW and NBW gendermatched littermates were either left to suckle the sow or transferred to a nursery at the age of $3 \mathrm{~d}$ and had ad libitum access to a milk replacer that was refreshed twice a day (Table 1). Milk replacer was made by mixing $200 \mathrm{~g}$ of milk replacer powder into $1 \mathrm{~L}$ of water, preheated at $42{ }^{\circ} \mathrm{C}$. This resulted in a dry matter (DM) content of $193 \mathrm{~g} / \mathrm{kg}$ milk. This is comparable with the DM content of sow milk, which is around 170 to $190 \mathrm{~g} / \mathrm{kg}$ milk between $3 \mathrm{~d}$ and $42 \mathrm{~d}$ of lactation [34]. In Table 1, the calculated nutrient composition of some important nutrients is shown, expressed on DM basis. When account for the dilution factor, it is possible to compare this milk formula with sow milk. For instance, it is clear

Table 1 Composition of the milk replacer used for piglets from $3 \mathrm{~d}$ of age until weaning at $\mathrm{d} 19$

Ingredient composition, \%

\begin{tabular}{ll} 
Coco fat filled whey 50/50 & 42.00 \\
Skimmed milk powder & 17.61 \\
Whey permeate & 8.29 \\
Soy protein concentrate Soycomil K & 10.00 \\
Cheddar whey powder & 8.29 \\
Whey protein concentrate80, DVN & 7.00 \\
Spray dried blood plasma P80 & 4.00 \\
Dicalciumphosphate 18\% P & 0.32 \\
DL-Methionine & 0.31 \\
Citric acid & 0.30 \\
L-Tryptophan & 0.08 \\
Vitamin and mineral premix & 1.8 \\
Calculated nutrient levels & \\
NEv(1997) MJ/kg & 15.48 \\
CP, g/kg & 249 \\
CF, g/kg & 110 \\
dLYS, g/kg & 18.2 \\
dMET + CYS, g/kg & 11.5 \\
dTHR, g/kg & 11.2 \\
dTRY, g/kg & 4.1 \\
\hline
\end{tabular}

${ }^{a}$ The mineral and vitamin premix supplied as the following (per kg diet): Vitamin A, 30, $000 \mathrm{IU}$; Vitamin $\mathrm{D}_{3}, 5000 \mathrm{IU}$; Vitamin E; $75 \mathrm{mg} ; \mathrm{Fe}^{2+}, 120 \mathrm{mg} ; \mathrm{Zn}^{2+}$, $35 \mathrm{mg} ; \mathrm{Cu}^{2+}, 135 \mathrm{mg} ; \mathrm{Mn}^{2+}, 45 \mathrm{mg} ; \mathrm{Se}^{6+}, 350 \mu \mathrm{g} ; \mathrm{l}$, 1 mg, BHT, $75 \mathrm{mg} / \mathrm{kg}$ 
that the crude protein level in the formula $(49.8 \mathrm{~g} / \mathrm{kg}$ milk) is low but comparable with what can be expected in sow milk (51-64 g/kg milk) ([34-36]). The crude fat content was calculated at $22 \mathrm{~g} / \mathrm{kg}$ milk, which is considerably lower than the crude fat content of sow milk (5.3-6.5 $\mathrm{g} / \mathrm{kg}$ milk) [34-36]. In contrast, the total amount of lactose in the liquid milk replacer was $80 \mathrm{~g} / \mathrm{kg}$ milk. Values for sow milk range from 48 to $59 \mathrm{~g} / \mathrm{kg}$ milk, and thus are lower than what was offered to the formula fed piglets. From this, it might be clear that the milk formula was not completely comparable to the nutrient composition of porcine milk. However, this tailor made milk formula was meant as a compromise of many existing, commercially available milk replacer formulas, and as a copy of sow milk as such. A maximum of 4 NBWLBW gender matched littermate pairs were co-housed. The starting ambient temperature was $32{ }^{\circ} \mathrm{C}$ and linearly decreased to $28{ }^{\circ} \mathrm{C}$ towards $\mathrm{d} 19$ post-natal. Heating and ventilation was automatically controlled in function of the temperature settings. Six pairs of sow-reared LBW and NBW piglets were sampled on $\mathrm{d} 0, \mathrm{~d} 3, \mathrm{~d} 8$ and $\mathrm{d} 19$ of age, and 6 pairs of artificially reared LBW and NBW piglets were sampled on d5, d8 and d19 of age. Piglets sampled on $\mathrm{d} 0$ were removed from the sow between 12 and $24 \mathrm{~h}$ after parturition. At d3, intramuscular iron injections were given (Iron(III) Dextran, $200 \mathrm{mg} /$ piglet, Uniferon). The selected animals did not receive any antibiotic treatment prior or during the experiment.

Pigs were killed by exsanguination by severing the carotid arteries and jugular veins following induction of terminal anesthesia by intramuscular injection of ketamine $(15 \mathrm{mg} / \mathrm{kg} \mathrm{BW})$ combined with xylazine $(2 \mathrm{mg} / \mathrm{kg}$ $B W)$. All piglets were weighed prior to euthanasia.

Blood was collected in EDTA and heparinized tubes containing supplemental bathophenanthroline disulfonate sodium salt. Erythrocytes were isolated by centrifuging $(3000 \times \mathrm{g}, 15 \mathrm{~min}) 0.5 \mathrm{~mL}$ of unclotted, heparinized blood. After removing the plasma, erythrocytes were lysed by adding $100 \mu \mathrm{L}$ of a $70 \%$ metaphosphoric acid solution, $600 \mu \mathrm{L}$ milli $\mathrm{Q}$ and intense vortexing. These extracts were then centrifuged (3000 $\times \mathrm{g}, 15 \mathrm{~min}$ ), and $0.5 \mathrm{~mL}$ of the remaining acid extract was transferred to a vial containing $50 \mu \mathrm{L}$ of a $\gamma$-gluglu internal standard solution. After opening the abdomen, the liver was isolated and samples of the left lateral lobe were dissected for acid and phosphate buffered aqueous extraction, as described for the small intestinal mucosa. Subsequently, the small intestine (SI), defined as the part of the gastrointestinal tract between the pylorus and the ileocecal valve, was dissected and its length was measured. A $10 \mathrm{~cm}$ segment of proximal and distal SI (5 and 75\% of total SI length, respectively) was taken for Ussing chamber measurements. In addition, $20 \mathrm{~cm}$ segments at 5 and $75 \%$ of the total SI length were emptied and carefully flushed with saline. The tissue of these $20 \mathrm{~cm}$ segments was placed on an ice-cold surface and the mucosa was retrieved by gently scraping the mucosal surface with a glass slide. Aliquots of the mucosa were either used instantaneously for acid and phosphate buffered aqueous extracts or transferred to plastic $2 \mathrm{~mL}$ screwcapped tubes, snap-frozen in liquid nitrogen and stored at $-80{ }^{\circ} \mathrm{C}$ pending redox state analysis. Furthermore, $5 \mathrm{~cm}$ segments at 5 or $75 \%$ of the total SI length were taken, flushed with saline, snap-frozen in liquid nitrogen and stored at $-80{ }^{\circ} \mathrm{C}$ pending protein expression analysis. Finally, a $5 \mathrm{~cm}$ segment at 5 or $75 \%$ of the total SI length was flushed with saline, divided in smaller pieces of max $1.5 \mathrm{~cm}$ in length and fixated for $2 \mathrm{~h}$ in $4 \%$ freshly prepared paraformaldehyde (in $0.01 \mathrm{~mol} / \mathrm{L}$ phosphate-buffered saline) (volume tissue/ volume fixative: 1/5) and routinely processed for paraffin-embedding [37].

\section{Small intestinal histo-morphological measurements}

In brief, $4 \mu \mathrm{m}$ sections of paraffin-embedded samples were mounted on slides and stained with hematoxylineosin. Villus height, mid-villus width, and crypt depth were measured at $10 \times$ magnification using an Olympus BX61 microscope and image analysis software (analySIS Pro, Olympus Belgium, Aartselaar, Belgium) in 1-3 welloriented villi and associated crypts in at least $12-15$ sections per tissue sample, to yield 30 measurements per small intestinal region.

\section{Small intestinal protein expression profile analysis}

The concentration of specific tight junction proteins and markers for apoptosis and mitosis of the proximal and distal intestinal tissue samples was investigated using commercially available enzyme-linked immunosorbent assays (ELISA) of occludin (SEC228Hu), claudin-3 (SEF293Hu), proliferating cell nuclear antigen (PCNA) (SEA591Hu) and caspase-3 (SEA626Hu) (Cloud-Clone Corporation', Houston, TX, USA). All tissue samples were crushed, dissolved in phosphatebuffered saline solution (PBS, $\mathrm{pH} 7.4,0.01 \mathrm{~mol} / \mathrm{L}$ ), sonicated 6 times for $5 \mathrm{~s}$ at $4{ }^{\circ} \mathrm{C}$ (Sonics Vibracell ${ }^{\mathrm{mx}}$, VCX130, Newtown CT, USA), and kept on ice for $30 \mathrm{~min}$. Subsequently the samples were centrifuged for $2 \mathrm{~min}$ at $13,400 \mathrm{rpm}$ at $4{ }^{\circ} \mathrm{C}$ (Heraeus X3R with TX750, Thermo Scientific, Rockford, USA), after which the supernatant was isolated, total protein concentration was determined using a Pierce TM BCA Protein Assay Kit (Thermo Scientific, Rockford, USA) and finally the samples were diluted to a total protein concentration of $10 \mathrm{ng} / \mu \mathrm{L}$. Then, samples were processed on a sandwich ELISA plate and the experiment was performed according to the manufacturer's instructions. Absorbance was 
measured using an Infinite M200 Pro spectrophotometer with X-Fluor software at $450 \mathrm{~nm}$ at $25{ }^{\circ} \mathrm{C}$ (Tecan Group Ltd., Männedorf, Switzerland). Values of protein expression were determined per gram of total protein in a sample, measured using a Pierce ${ }^{\mathrm{TM}}$ BCA Protein Assay Kit (ThermoFisher Scientific, Belgium), and expressed as $\mathrm{fmol} / \mathrm{mg}$.

\section{Ex vivo measurement of small intestinal permeability}

Intestinal mucosal permeability was assessed ex vivo by measuring the translocation of macromolecular markers using the Ussing chamber technique. The segments were first rinsed with saline. The mucosal layer was stripped from the seromuscular layer and pinned onto $1.07 \mathrm{~cm}^{2}$ sliders that were mounted into modified Ussing chambers (Dipl.-Ing. Mußler Scientific Instruments, Aachen, Germany). All tissues were mounted within $10 \mathrm{~min}$ following euthanasia. Tissues were immersed in $6.5 \mathrm{~mL}$ Ringer solution $(115 \mathrm{mmol} / \mathrm{L} \mathrm{NaCl}, 5 \mathrm{mmol} / \mathrm{L} \mathrm{KCl}$, $25 \mathrm{mmol} / \mathrm{L} \mathrm{NaHCO} 3,2.4 \mathrm{mmol} / \mathrm{L} \mathrm{Na}_{2} \mathrm{HPO}_{4}, 0.4 \mathrm{mmol} / \mathrm{L}$ $\mathrm{NaH}_{2} \mathrm{PO}_{4}, 1.25 \mathrm{mmol} / \mathrm{L} \mathrm{CaCl}, 1 \mathrm{mmol} / \mathrm{L} \mathrm{MgSO}_{4}$ ) with $6 \mathrm{mmol} / \mathrm{L}$ of mannitol or glucose in the luminal and serosal side, respectively. The system was water-jacketed to $37{ }^{\circ} \mathrm{C}$ and oxygenated with $95 \% \mathrm{O}_{2}$ and $5 \% \mathrm{CO}_{2}$. After an equilibration period of $20 \mathrm{~min}, 4 \mathrm{kDa}$ fluorescein isothiocyanate-dextran (FD-4, Sigma-Aldrich, Bornem, Belgium) and $40 \mathrm{kDa}$ horseradish peroxidase (HRP, type IV, Sigma-Aldrich, Bornem, Belgium) were added to the mucosal side to a final concentration of $0.8 \mathrm{mg} / \mathrm{mL}$ of FD4 and $0.4 \mathrm{mg} / \mathrm{mL}$ of HRP. Samples of the buffer solution were taken from the serosal chamber at 20, 40, 60 and $100 \mathrm{~min}$ after adding markers. Meanwhile, the same volume of buffer was taken from the mucosal side to keep the volume balance across sides. Fluorescence intensity of FD-4 in the medium was measured at excitation wavelength of $485 \mathrm{~nm}$ and emission wavelength of $538 \mathrm{~nm}$ using a fluorescence plate reader (Thermo Scientific, Marietta, OH, USA). HRP was measured according to the method described previously [38]. In short, HRP activity was measured by adding a 'start solution' $(50 \mathrm{~mL}$ of $0.2 \mathrm{~mol} / \mathrm{L} \quad \mathrm{NaH}_{2} \mathrm{PO}_{4}, 1 \mathrm{~mL}$ of $0.2 \mathrm{~mol} / \mathrm{L} \mathrm{Na}_{2} \mathrm{HPO}_{4}$, $20.4 \mu \mathrm{L}$ of $30 \% \mathrm{H}_{2} \mathrm{O}_{2}, 1.7 \mathrm{~mL}$ of $1 \%$ dianisidine peroxide substrate, made up to $204 \mathrm{~mL}$ with water) to the HRP samples and left for $10 \mathrm{~min}$, after which the reaction was terminated by addition of $120 \mu \mathrm{L}$ of $4 \%$ sodium azide and the absorbance was read at $460 \mathrm{~nm}$. The relation between peroxidase concentration and absorbance is linear in the concentration range 10-100 $\mathrm{pmol} / \mathrm{L}$. The apparent permeation coefficient (Papp) was calculated as:

$$
\operatorname{Papp}(\mathrm{cm} / \mathrm{s}):(\mathrm{dc} / \mathrm{dt}) \times \mathrm{V} / \mathrm{c}_{0} / \mathrm{A},
$$

Whereby $\mathrm{dc} / \mathrm{dt}$ is the change of serosal concentration in the 20- to $100-\min$ period $(\mathrm{cm} / \mathrm{s}) ; \mathrm{V}$ is the volume of the chamber, $\mathrm{c}_{0}$ is the initial marker concentration in the mucosal reservoirs and A the area of the exposed intestine in the chambers $\left(\mathrm{cm}^{2}\right)$.

\section{Mucosal, liver and blood homogenate extracts and biochemical assays}

An acid extract was prepared from $1 \mathrm{~g}$ of homogenized (Braun homogenizer at $900 \mathrm{rpm}$ ) intestinal mucosa or liver that was placed in $10 \mathrm{~mL}$ ice-cold perchloric acid (PCA) $10 \%$ solution and centrifuged at $15,000 \times \mathrm{g}$ for $15 \mathrm{~min}$ at $4{ }^{\circ} \mathrm{C}$. The resulting acid extract $(0.5 \mathrm{~mL})$ was transferred to tubes containing $50 \mu \mathrm{L} \gamma$-glu-glu internal standard solution. Samples were snap frozen in liquid nitrogen and stored at $-80{ }^{\circ} \mathrm{C}$ until analysis of GSH and glutathione disulfide (GSSG). The biuret reaction was applied to determine the total protein content. Mucosal GSH and GSSG were measured using a modified high performance liquid chromatography (HPLC) method $[39,40]$. The derivation procedure included the reaction of $100 \mathrm{mmol} / \mathrm{L}$ iodoacetic acid solution with thiols to form S-carboxymethyl derivatives followed by chromophore derivation of primary amines with dinitrofluorobenzene (DNFB, 1\% (v/v) in ethanol). GSH and GSSG were separated through EC250/4.6 Nucleosil 120-7 $\mathrm{NH}_{2}$ aminopropyl column (Machery-Nagel, Düren, Germany) protected by the same $\mathrm{NH}_{2}$ guard column (CC8/4). Chromatographic runs were performed at a flow-rate of $1.5 \mathrm{~mL} / \mathrm{min}$, starting at $80 \%$ solvent $\mathrm{A} / 20 \%$ solvent $\mathrm{B}$ for $5 \mathrm{~min}$ followed by a 10 min linear gradient to $1 \%$ solvent $\mathrm{A} / 99 \%$ solvent $\mathrm{B}$ and a $10 \mathrm{~min}$ isocratic period at $1 \%$ solvent $\mathrm{A} / 99 \%$ solvent $B$ (solvent A: water-methanol solution $(1: 4, \mathrm{v} / \mathrm{v})$, solvent B: $0.5 \mathrm{~mol} / \mathrm{L}$ sodium acetate $-64 \%$ methanol). The column was re-equilibrated to the initial conditions for $15 \mathrm{~min}$ while maintaining the column temperature at $40{ }^{\circ} \mathrm{C}$. The UV detector was set at $365 \mathrm{~nm}$ for absorption measurements. GSH and GSSG were identified by retention times of authentic standards. Concentrations were determined by using the internal and external standards and expressed as $\mu \mathrm{mol} / \mathrm{g}$ protein. In addition, a phosphate buffered aqueous extract was made by mixing approximately $1 \mathrm{~g}$ of homogenized mucosa in $10 \mathrm{~mL}$ ice cold $1 \%$ Triton-X100 phosphate buffer solution $(\mathrm{pH}=7.0)$, by using an Ultra-Turrax dispensing machine (IKA-Werke $\mathrm{GmbH}$ \& Co. KG, Staufen, Germany). The supernatant was transferred to $2 \mathrm{~mL}$ tubes, snap frozen and stored at $-80{ }^{\circ} \mathrm{C}$ until analysis. Supernatants were used for the determination of GSH-Px activity and malondialdehyde (MDA; expressed as $\mathrm{nmol} / \mathrm{g}$ protein) concentration. Assessment of GSH-Px activity (expressed as U/g protein) in EDTA plasma and mucosa was determined spectrophotometrically [41]. The thiobarbituric acid reactive substances (TBARS) method was used to 
measure MDA concentration in EDTA plasma, liver and mucosa extracts [42].

\section{Statistical analysis}

Linear mixed models were fitted to assess the influence of birth weight category (NBW/LBW), feeding (artificially reared/sow-reared) and days postnatal (as a categorical variable) on the quantitative outcome variables. To model the dependence between observations within the same litter, random intercept terms for litter were added to the model. Depending on the research question, separate analyses were carried out in subgroups (e.g. only in sow-reared piglets) or time points were analyzed separately. In the subgroup analyses where no random effect terms was needed, a multiple linear regression model was fitted. Post hoc tests to compare mean values between the different time points (days postnatal) were carried out using Tukey's honestly significant difference. Models were fitted using the Mixed Model procedure of the JMP Pro11 software (SAS Institute, Cary, NC, USA). Significance for the fixed effects was tested using an F-test with Kenward-Roger correction. Data are expressed as means and their standard errors (S.E.), and $P<0.05$ was considered significant.

\section{Results}

\section{Body weight of piglets}

Average body weight of LBW and NBW piglets sampled at birth (d0) was $0.77 \pm 0.07$ and $1.29 \pm 0.08 \mathrm{~kg}$, respectively (Fig. 1). The body weight of both birth weight categories did not significantly change during the first 3 days. Afterwards, in both sow- and artificially reared piglets the body weight gradually increased $(P<0.001)$. At each point in time, LBW sow-reared piglets showed lower body

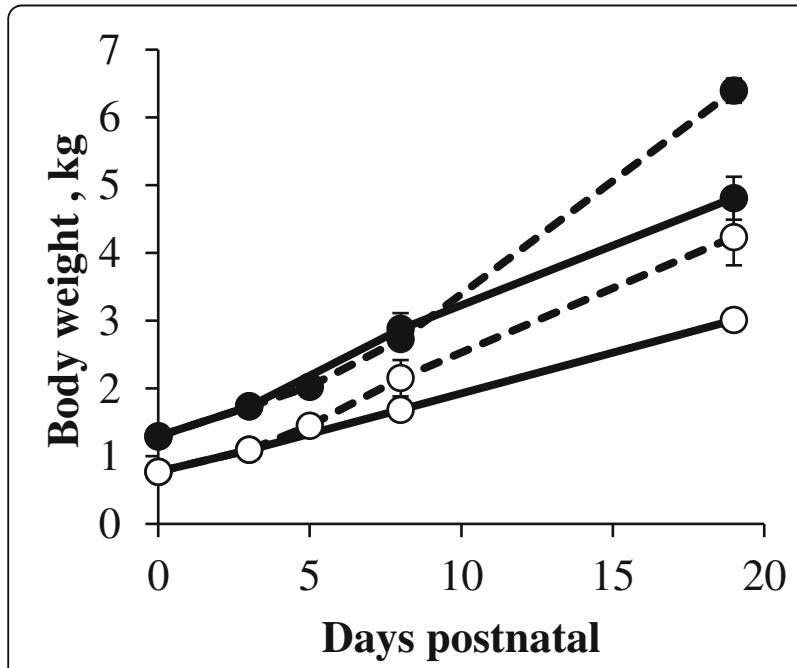

Fig. 1 Body weights (kg) of LBW (open circle) and NBW (closed circle) from sow- (full line) and artificially reared (dashed line) piglets during the suckling period. Values are means \pm SE $(n=6)$ weights compared to their NBW sow-reared littermates $(P<0.01)$. A similar observation was seen in artificially reared piglets at $\mathrm{d} 5(P<0.001)$ and $\mathrm{d} 19(P<0.05)$. Body weights of LBW and NBW artificially reared piglets were significantly higher, compared to respectively $\mathrm{LBW}$ and NBW sow-reared piglets at d19 $(P<0.05)$.

\section{Histo-morphological measurements in the proximal and} distal small intestine

The histo-morphological parameters were stable between $\mathrm{d} 0$ and $\mathrm{d} 3$ (Fig. 2). After d3, villus height significantly decreased $(P<0.05$; Fig. $2 \mathrm{a})$, whereas villus width $(P<0.05$; Fig. $2 \mathrm{~b})$ and crypt depth significantly increased $(P<0.05$; Fig. 2c). Furthermore, the transfer of piglets to a nursery caused villus atrophy in the proximal and distal $(P<0.05)$ SI from d3 to d5. Villi were significantly wider (at d19: $P<0.001$ ) and crypts deeper (at $\mathrm{d} 8$ and d19: $P<0.01)$ in artificially reared piglets compared to sow-reared piglets. In the distal SI of NBW sow-reared piglets villus heights were consistently higher compared to those of their LBW littermates $(P<0.05)$. In contrast, villus heights in the distal SI of NBW artificially reared piglets were on average $193 \mu \mathrm{m}$ lower at d19 compared to their LBW littermates $(P<0.05)$.

PCNA and caspase-3 protein expression in the proximal and distal small intestine

PCNA protein expression remained at the same level during the suckling period in the proximal and distal SI of sow-reared piglets (Fig. 3a). Transferring the piglets at d3 to a nursery significantly reduced PCNA protein expression in the proximal SI at $\mathrm{d} 5(P<0.05)$ as compared to $\mathrm{d} 3$, whereas in the distal SI its level remained unaffected. PCNA protein expression in the proximal and distal SI of artificially reared piglets was significantly lower compared to sow-reared piglets at $\mathrm{d} 8(P<0.05)$ and at $\mathrm{d} 19$ in the proximal SI $(P<0.001)$ (Fig. 3a).

Caspase-3 protein expression significantly decreased in the proximal SI of sow-reared $(P<0.05)$ and artificially reared piglets $(P<0.001)$ piglets from $\mathrm{d} 3$ to $\mathrm{d} 19$ (Fig. 3b). In contrast, in the distal SI of sow- and artificially reared piglets, no age-related differences were observed. Caspase-3 protein expression was significantly lower in the proximal $(P<0.05)$ and distal $(P<$ $0.05)$ SI of artificially reared piglets compared to sowreared piglets at $\mathrm{d} 19$.

Occludin and claudin-3 protein expression in the proximal and distal small intestine

Occludin expression in the proximal SI of sow-reared piglets decreased from $\mathrm{d} 3$ to $\mathrm{d} 19(P<0.001)$, whereas in the distal SI its level remained unchanged (Fig. 4a). Occludin expression dropped significantly in the proximal $(P<0.05)$ but not in the distal SI of artificially 

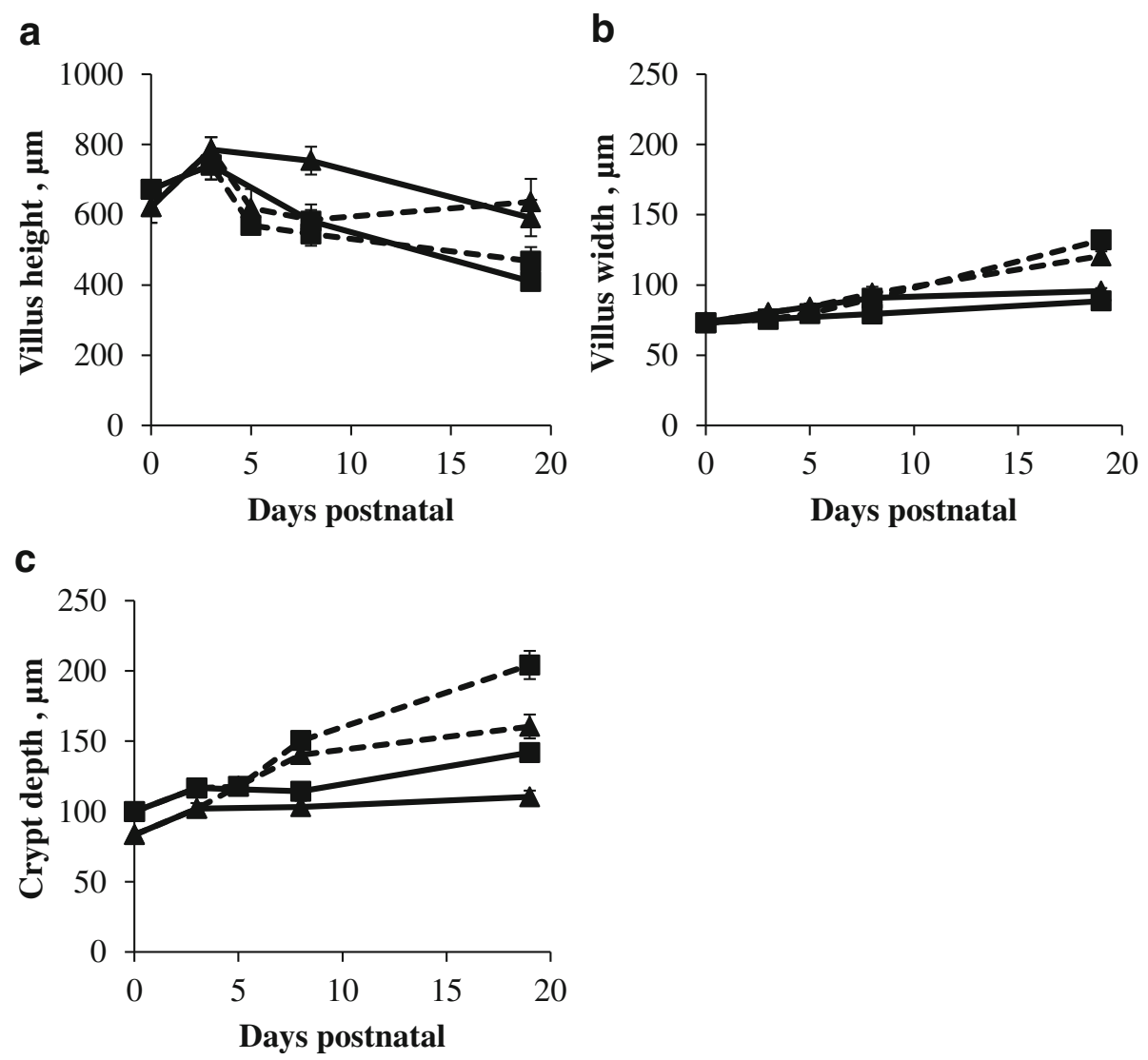

Fig. 2 Villus height $(\mu \mathrm{m})(\mathbf{a})$, villus width $(\mu \mathrm{m})(\mathbf{b})$ and crypt depth $(\mu \mathrm{m})(\mathbf{c})$ in proximal (square) and distal (triangle) SI of sow- (full line) and artificially reared (dashed line) piglets expressed as $\mu \mathrm{m}$. Values are means \pm SE ( $n=12$ as LBW and NBW piglets were pooled together)

reared piglets, from $\mathrm{d} 3$ to $\mathrm{d} 5$, but returned to its initial levels afterwards. The expression of occludin in the SI was comparable for sow- and artificially reared piglets.

Claudin-3 expression in the proximal and in the distal SI of artificially reared piglets dropped significantly from $\mathrm{d} 3$ to d5 $(P<0.01$; Fig. 4b). Claudin-3 expression increased from d5 to d19 and was significantly higher in the SI of artificially reared piglets compared to sow-reared piglets at $\mathrm{d} 19(P<$
0.01). Claudin-3 expression in the distal SI of LBW sowreared piglets was on average $33 \%$ higher compared to NBW sow-reared piglets at $\mathrm{d} 3$, d8 and $\mathrm{d} 19(P<0.01)$.

Ex vivo permeability in the proximal and distal small intestine

FD-4 and HRP permeability in the proximal and distal SI remained stable in sow-reared piglets (Fig. $5 \mathrm{a}$ and b). FD-4
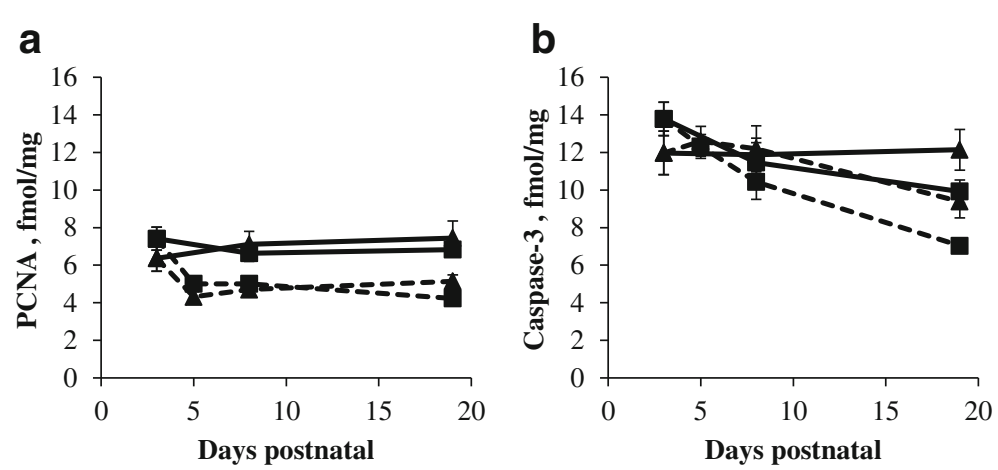

Fig. 3 Relative protein expression of PCNA (fmol/mg) (a) and caspase-3 (fmol/mg) (b) in the proximal (square) and distal (triangle) SI of sow- (full line) and artificially reared (dashed line) piglets. Values are means \pm SE ( $n=12$ as LBW and NBW piglets were pooled together) 

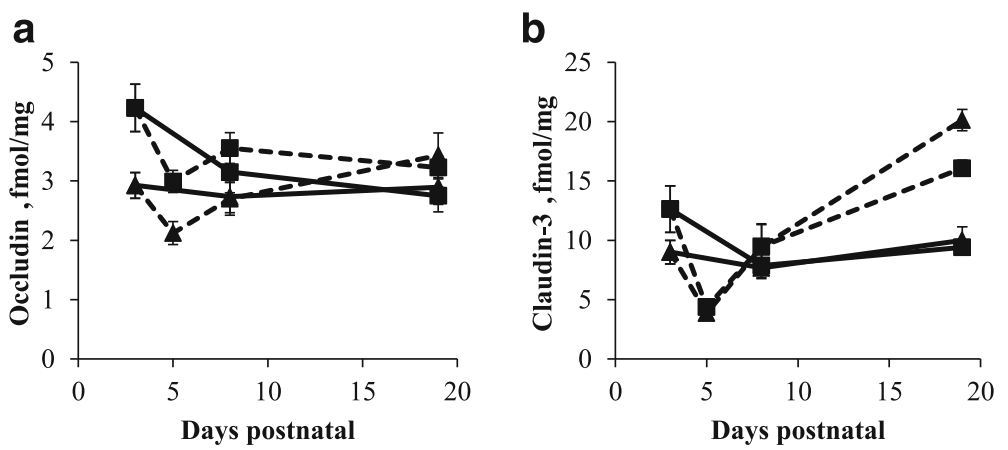

Fig. 4 Relative protein expression of occludin (fmol/mg) (a) and claudin-3 (fmol/mg) (b) in the proximal (square) and distal (triangle) SI of sow(full line) and artificially reared (dashed line) piglets. Values are means \pm SE ( $n=12$ as LBW and NBW piglets were pooled together)

permeability in the proximal SI significantly increased in 5-day-old NBW artificially reared piglets when transferred to a nursery at $\mathrm{d} 3(P<0.05$; Fig. 5a). Given the observation that the Papp of FD-4 was already high at 3 days of age in the proximal SI of LBW piglets, no changes could be observed after the start of artificial rearing. In the distal SI, both FD-4 $(P<0.05$; Fig. 5a) and HRP $(P<0.01$; Fig. 5b) permeabilities were significantly increased in both 5-dayold LBW and NBW artificially reared piglets, compared to d3. LBW sow-reared piglets consistently showed significantly higher FD-4 (proximal: on average $0.5 \times 10^{-6} \mathrm{~cm} / \mathrm{s}$ higher; distal: on average $0.2 \times 10^{-6} \mathrm{~cm} / \mathrm{s}$ higher) and HRP (proximal: on average $0.09 \times 10^{-6} \mathrm{~cm} / \mathrm{s}$ higher; distal: on average $0.06 \times 10^{-6} \mathrm{~cm} / \mathrm{s}$ higher) permeability when compared to their NBW littermates $(P<0.05)$. No such differences were observed in artificially reared piglets.

Mucosal redox state represented by GSH concentration, GSSG concentration, GSSG/GSH ratio, GSH-Px activity and MDA concentration

GSH concentration was constant from birth until d8. In the distal SI mucosa GSH concentrations remained stable SI, whereas in the proximal SI it decreased significantly after d8 $(P<0.01)$ of sow-reared piglets (Fig. 6a). The concentration of GSSG and the GSSG/GSH ratio did not show any age-related changes in sow-reared piglets $(P>0.05$; Fig. $6 \mathrm{~b}$ and $\mathrm{c})$. The activity of GSH-Px in the proximal and distal SI mucosae of sow-reared piglets increased from birth until d3 $(P<0.05)$. After d8, GSH-Px activity decreased significantly $(P<0.01)$, reaching a similar activity at d19 as observed at birth (Fig. 6d).

In the proximal intestine of sow-reared pigs, the concentration of MDA abruptly dropped after birth $(P<0.001$; Fig. 6e $)$ and remained stable from d3 until $\mathrm{d} 19$, whereas in the distal intestine the decrease was more spread out in time $(P<0.01)$. Transferring piglets to a nursery decreased the concentration of GSH, whereas the GSSG concentration and GSSG/GSH ratio were increased in the SI of artificially reared piglets at $\mathrm{d} 5$. In the proximal SI of artificially reared piglets GSH concentration peaked, while GSSG concentration and GSSG/GSH ratio showed a minimum at d8 $(P<0.05)$. However by $\mathrm{d} 19$, these redox parameters returned to the values noted at birth $(P<0.05)$. GSH-Px activity showed a minimum at $\mathrm{d} 5(P<0.05)$, but recovered from $\mathrm{d} 8$ to $\mathrm{d} 19(P<0.01)$ in the SI of artificially reared piglets.
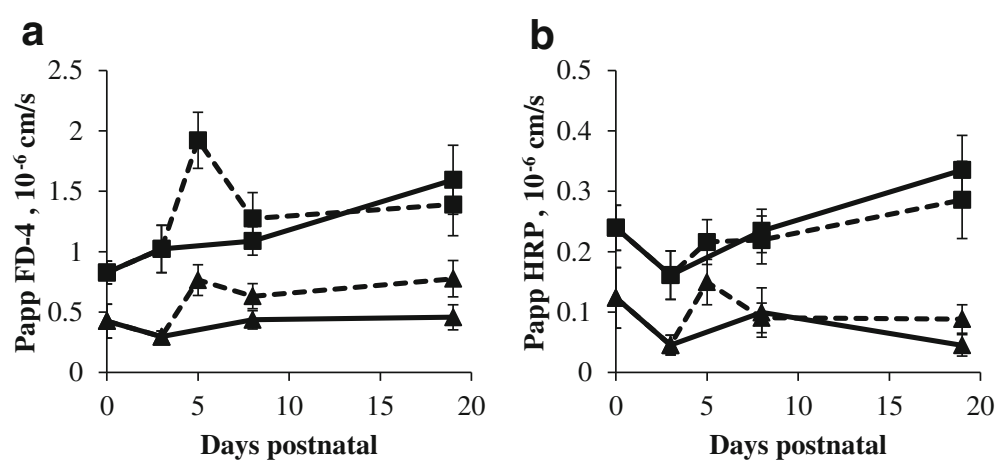

Fig. 5 Intestinal permeability indicated by the Papp of FD-4 $\left(10^{-6} \mathrm{~cm} / \mathrm{s}\right)(\mathbf{a})$ and HRP $\left(10^{-6} \mathrm{~cm} / \mathrm{s}\right)(\mathbf{b})$ in the proximal (square) and distal SI (triangle) of sow- (full line) and artificially reared (dashed line) piglets. Values are means $\pm \mathrm{SE}(n=6)$ 

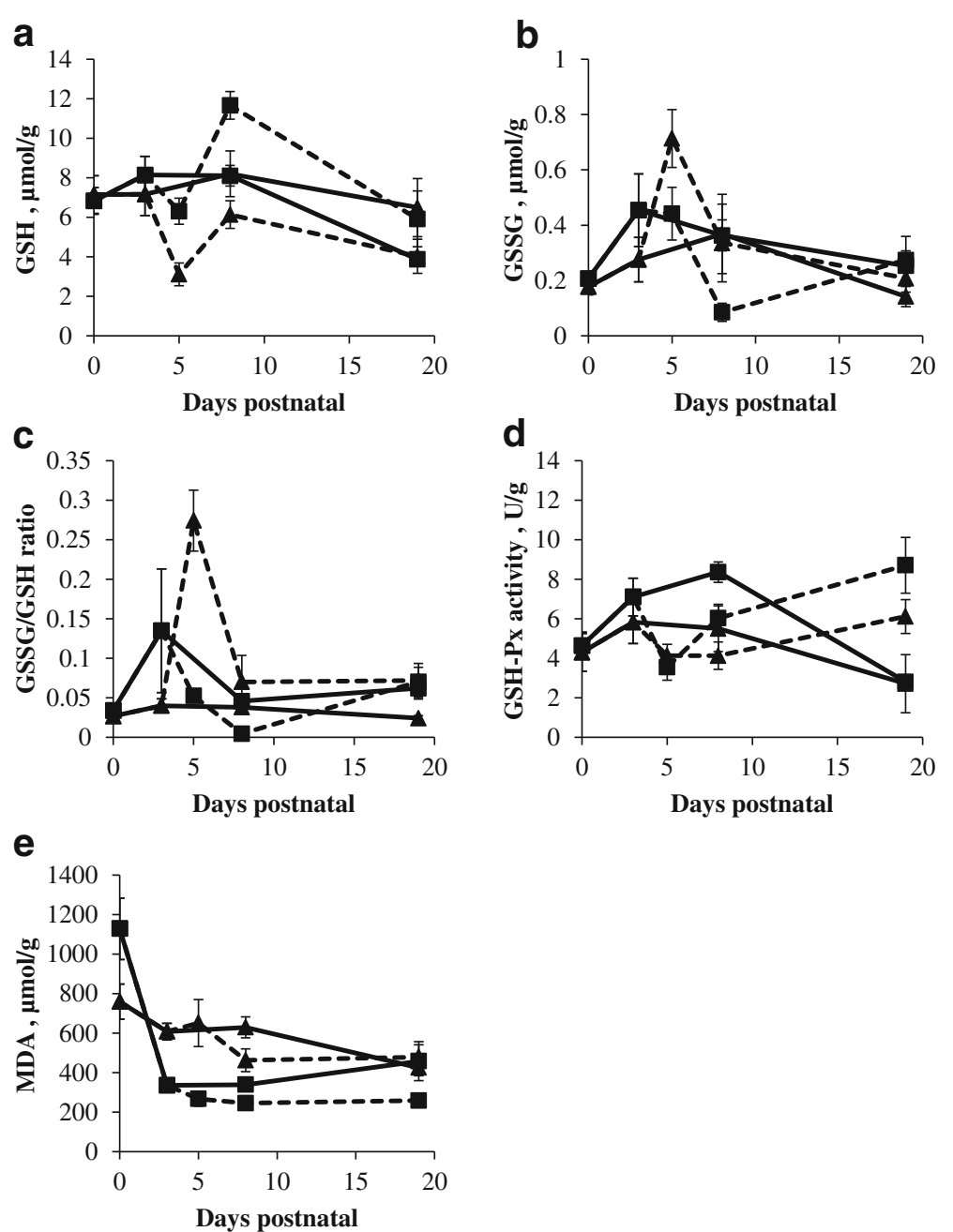

Fig. 6 Mucosal GSH concentration ( $\mu \mathrm{mol} / \mathrm{g})(\mathbf{a})$, GSSG concentration $(\mu \mathrm{mol} / \mathrm{g})(\mathbf{b})$, GSSG/GSH ratio $(\mathbf{c})$ and GSH-Px activity (U/g) (d), MDA concentration $(\mu \mathrm{mol} / \mathrm{g})(\mathbf{e})$ of the proximal (square) and distal SI (triangle) in sow- (full line) and artificially reared (dashed line) piglets. Values are means \pm SE ( $n=12$ as LBW and NBW piglets were pooled together)

In the proximal SI, GSH concentration was significantly higher $(P<0.05)$, while GSSG concentration $(P<0.01)$ and consequently the GSSG/GSH ratio $(P=0.001)$ was significantly lower in artificially reared piglets compared to sowreared piglets at $\mathrm{d} 8$. GSH-Px activity was significantly lower at $\mathrm{d} 8(P<0.001)$ and significantly higher at $\mathrm{d} 19$ $(P<0.001)$ in both regions of the SI of artificially reared piglets compared to sow-reared piglets. GSHPx activity in the SI of LBW sow-reared piglets was significantly higher than their NBW littermates (proximal: on average $1.38 \mathrm{U} / \mathrm{g}$ higher; distal: on average $0.64 \mathrm{U} / \mathrm{g}$ higher $)(P<0.001)$. A similar observation for both birth weight categories was made in the distal SI of artificially reared piglets (on average 1.24 higher, $P<0.01$ ).

At d8, MDA concentration in the proximal SI of sowreared piglets was significantly higher compared to artificially reared piglets $(P<0.01)$.
Liver redox state represented by GSH concentration, GSSG concentration, GSSG/GSH ratio, GSH-Px activity and MDA concentration

Liver GSH concentration, GSSG/GSH ratio and GSH-Px activity in sow-reared piglets did not significantly change (Fig. 7a, c and d). GSSG concentration decreased significantly from d0 to d3 $(P<0.05$; Fig. $7 b)$ in sow-reared piglets and returned to concentrations seen at birth afterwards (Fig. 7b). MDA concentration showed a significant increase after $\mathrm{d} 3$ in both LBW and NBW piglets $(P<0.05$; Fig. $7 \mathrm{e})$.

When piglets were introduced to a milk replacer, GSH $(P<0.05)$ and GSSG $(P<0.01)$ concentrations significantly decreased whereas GSSG/GSH ratio $(P<0.05)$ and MDA concentration $(P<0.001)$ significantly increased from $\mathrm{d} 3$ to d5. Meanwhile, GSH-Px activity remained unchanged. All redox parameters in the liver were stable from $\mathrm{d} 5$ to 

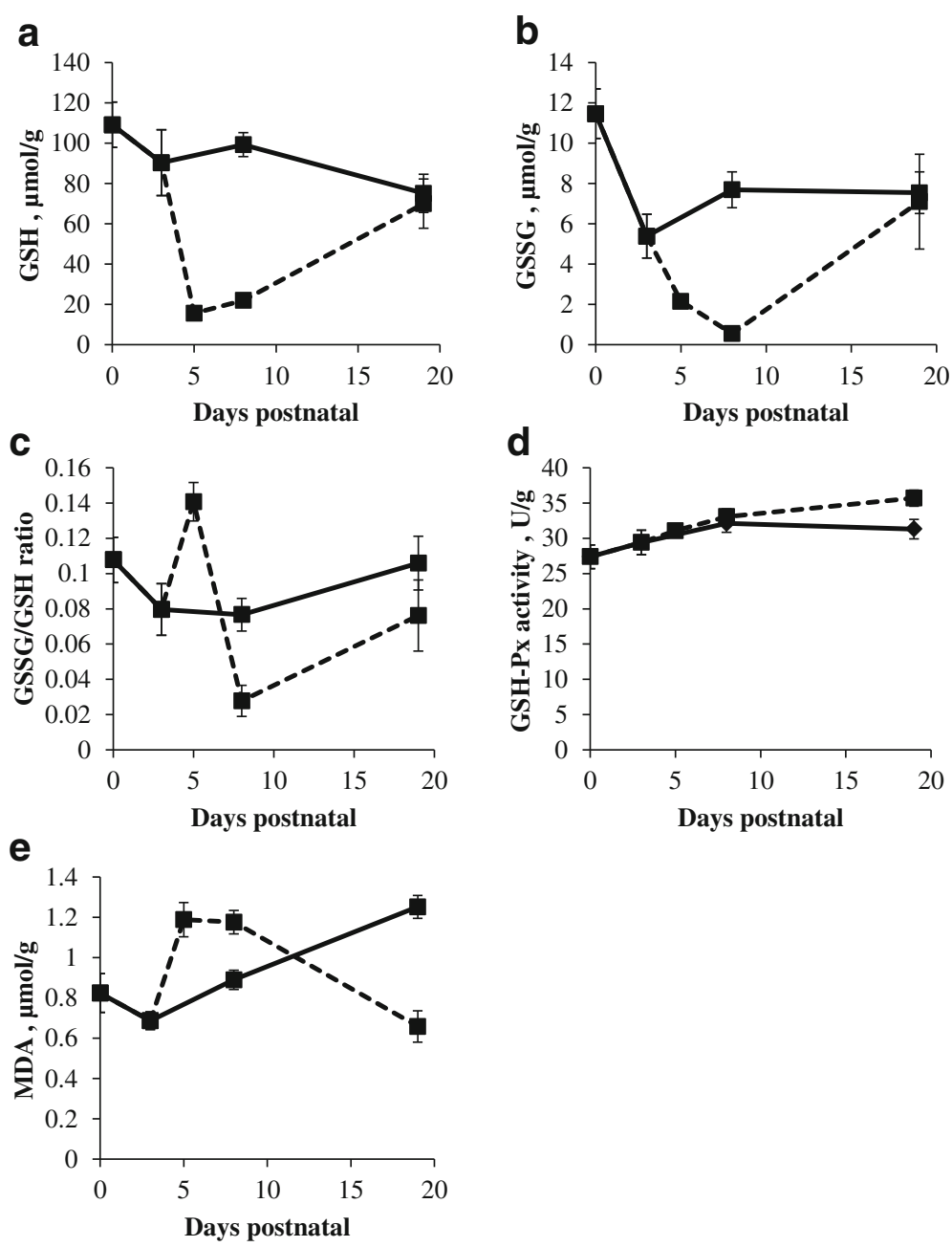

Fig. 7 Liver GSH concentration ( $\mu \mathrm{mol} / \mathrm{g})$ (a) and GSSG concentration ( $\mu \mathrm{mol} / \mathrm{g})(\mathbf{b}), \mathrm{GSSG} / \mathrm{GSH}$ ratio $(\mathbf{c}), \mathrm{GSH}-\mathrm{Px}$ activity $(\mathrm{U} / \mathrm{g})(\mathbf{d})$ and MDA ( $\mu \mathrm{mol} / \mathrm{g})$ (e) in sow- (full line) and artificially reared (dashed line) piglets. Values are means \pm SE ( $n=12$ as LBW and NBW piglets were pooled together)

$\mathrm{d} 8$ in artificially reared piglets, except GSSG/GSH ratio that showed a significant decrease $(P<0.01)$. Towards d19, GSH concentration $(P<0.01)$ and GSH-Px activity $(P<0.05)$ significantly increased while MDA concentration $(P<0.01)$ significantly decreased in artificially reared piglets.

At d8, a lower GSH concentration and a higher MDA were observed in artificially reared piglets compared to sow-reared piglets $(P<0.001)$. At d19, higher GSH-Px activities were observed in artificially reared piglets compared to sow-reared piglets $(P<0.01)$.

Systemic redox state represented by GSH concentration, GSSG concentration, and GSSG/GSH ratio, GSH-Px activity and MDA concentration

The GSH-Px activity gradually, significantly increased during the investigated time frame in both sow- and artificially reared piglets $(P<0.01$; Fig. $8 \mathrm{~d})$. GSH concentration in erythrocytes significantly increased in artificially reared piglets $(P<0.01)$ from $\mathrm{d} 5$ to $\mathrm{d} 19$, but remained constant in sow-reared piglets from d0 to d19 (Fig. 8a). Plasma MDA concentration decreased $6.77 \mu \mathrm{mol} / \mathrm{g}$ during the first 3 days of life in LBW piglets $(P<0.01$; Fig. 8e). Plasma GSH-Px activity was significantly lower in artificially reared piglets compared to sow-reared piglets at $\mathrm{d} 8$ and d19 $(P<0.05)$. At d19, GSH-Px activity was still lower when LBW piglets were artificially reared $(P<0.05)$. Erythrocyte GSSG concentrations $(P<0.01$; Fig. $8 \mathrm{~b})$ and GSSG/GSH ratio $(P<0.05$; Fig. $8 \mathrm{c})$ were significantly increased at $\mathrm{d} 5$ when artificially reared piglets were transferred to a nursery at $\mathrm{d} 3$ (Fig. $8 \mathrm{~b}$ and $\mathrm{c}$ ). The concentration of GSH $(P<0.01)$ and GSSG $(P<0.05)$ significantly increased in artificially reared piglets from d5 to d19. At d19, GSH concentration and GSSG concentration were significantly higher in artificially reared when compared to sow-reared piglets $(P<0.05)$. GSH concentration was 

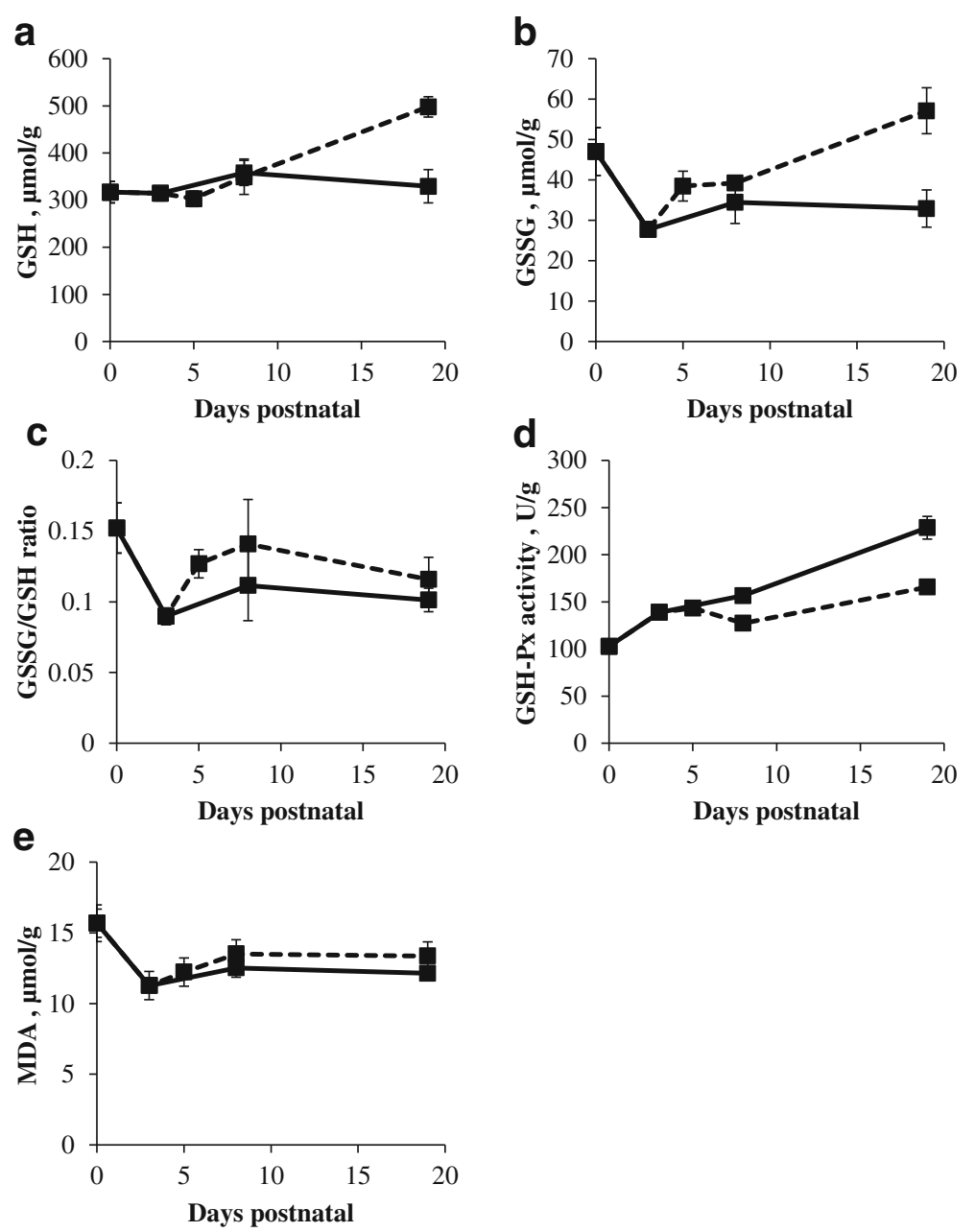

Fig. 8 Systemic GSH concentration ( $\mu \mathrm{mol} / \mathrm{g})(\mathbf{a})$, GSSG concentration ( $\mu \mathrm{mol} / \mathrm{g})(\mathbf{b})$, GSSG/GSH ratio (c), GSH-Px activity (U/g) (d) and MDA concentration ( $\mu \mathrm{mol} / \mathrm{g})$ (e) in sow- (full line) and artificially reared (dashed line) piglets. Values are means \pm SE $(n=12$ as LBW and NBW piglets were pooled together)

significantly lower in LBW sow-reared piglets when compared to their NBW littermates. $(P<0.05)$.

\section{Discussion}

Given the need for an alternative rearing strategy that lowers the challenges that LBW and supernumerary piglets face during the suckling period, we aimed to investigate the responses to full artificial rearing. Our data demonstrated that artificial rearing beneficially affected piglet performance, notwithstanding impairing effects on small intestinal architecture, permeability and redox state in both LBW and NBW piglets.

\section{Artificial rearing influences piglet performance}

This study documents the implications of full artificial rearing of LBW and supernumerary piglets. Under standard rearing conditions these pigs are at high risk of succumbing due to insufficient nutrient intake, increased disease susceptibility, and physiological deficits (e.g. lower energy reserves) [1]. Our study demonstrated that transitioning piglets to a nursery with ad libitum access to a milk replacer led to significantly higher body weights of LBW and NBW piglets compared to sowreared piglets at $\mathrm{d} 19$. The experiment was terminated on the same day as when the conventionally reared piglets were weaned on the farm with a 3-week batch system. For this specific farm, the average age at weaning is 19.6 d. Furthermore, milk production of the sow strongly decreases towards the end of the suckling phase. Around d 18-19, sow milk starts to be very limiting and becomes hard to compare to the ad libitum access for the artificially reared piglets [43]. Using a weighsuckle-weigh technique, De Vos et al. [26] showed that piglets with ad libitum access to milk replacer have a higher relative energy intake compared to sow-reared piglets [28]. Our findings confirm this and other 
previous research where LBW piglets receiving an energy rich diet-comparable with our LBW piglets fed a milk replacer ad libitum-presented a comparable body weight gain as NBW piglets receiving a lower energy intake-comparable with our NBW piglets fed by the sow [44]. In addition, the milk replacer used in our study contained spray-dried plasma which could have contributed further to the higher weight gain in the artificially reared group. Ermer et al. [45] showed that spray-dried porcine plasma increased feed intake. Thus next to ad libitum access to feed, diet composition cannot be neglected.

\section{Artificial rearing influences small intestinal architecture}

Small intestinal morphology is one of the major indicators reflecting gut health in pigs [46]. However, caution should be taken when evaluating morphology alone as a measure of gut health. For example, Enterotoxigenic Escherichia coli, the major causal agent of neonatal diarrhea, may occur without histological changes in the intestine [47]. Notwithstanding, stereological analysis of small intestinal morphology will provide the most accurate estimation of the intestinal absorptive surface area [48], a proxy of the surface can be calculated using villus height and villus width [47]. In our study, the mucosal surface area of the proximal small intestine at d19 was markedly larger in artificially reared piglets than sowreared piglets. In this regard, feeding a milk replacer shows promise as the increased mucosal surface suggests a higher ability to absorb nutrients. Moreover, previous research showed an increased activity of maltase and sucrase when piglets are fed a milk replacer [49-51]. Thus, artificial rearing seems to improve the digestive capacity at the level of the small intestine.

The deepening of the crypts could be a response to promote mucus secretion rather than lead to enterocyte maturation and proliferation and thus an increase in PCNA expression. Previous research showed that breastfed infants showed a delay in the mucin degradation when compared to artificially reared infants [52]. Phillips [53] showed that crypt goblet cells have the ability to restitute the mucus layer and showed a decrease in the percentage of villus epithelial volume occupied by mucin secretory granules.

Transferring piglets to a nursery at $\mathrm{d} 3$ exposed them to stressful effects caused by psychological, environmental or nutritional factors similar to those encountered during the conventional weaning process [54]. However, it is difficult to unravel the separate contributions of these factors. Previous studies showed significant villus atrophy at $\mathrm{d} 4$ and deeper crypts at $\mathrm{d} 7$ in piglets that were separated from the sow and still fed sow's milk compared to unweaned piglets $[55,56]$. Similarly, our study showed transient villus atrophy in piglets transferred to a nursery at $\mathrm{d} 3$. This villus height reduction is analogue to the intestinal morphological changes as a result of inadequate food intake immediately after conventional weaning [56-59]. In contrast to conventional weaning, villus length is rapidly restored. This could be related to the inclusion of spray-dried plasma in the milk replacer since this is known to increase villus height $[8,60-63]$.

\section{Artificial rearing affects small intestinal tight junction protein expression}

We hypothesized that artificial rearing influences small intestinal physiology. The intestinal epithelium plays a critical role in the transport of nutrients and macromolecules. At the same time, it has to provide an effective barrier to harmful macromolecules and microorganisms [64]. Epithelial cells constitute a dynamic barrier where large molecules can be transported by transcytosis and this can be measured by HRP [65]. Tight junctions (TJs) are essential components of the physical intercellular barrier and their presence and functionality changes under different physiological and pathological conditions $[66,67]$. Well-formed TJs are characterized by low solute permeability which can be determined by measuring FD-4 permeability [65]. The family of junctional adhesion molecules, the claudin and occludin families, are structural transmembrane $\mathrm{TJ}$ components that have the potential to mediate cell-cell adhesion [66, 68]. Within TJs, claudins are the main determinants of the selective pore properties $[68,69]$, while the role of occludin in barrier functioning is more diverse [70, 71]. In mice, the expression of claudin-3 is promoted during the first 3 weeks of life concomitant with the establishment of the intestinal microbiota $[72,73]$. Our study showed that claudin-3 expression rose particularly in artificially reared piglets. Possibly the different microbiota fingerprint [74] and the absence of milk born IgA's [34] can be held responsible. Claudin-3 is known to be a "tightening" claudin [75]. This could explain why permeability is seemingly unaffected by the observed increase in claudin-3. However, at the start of artificial rearing, claudin-3 as well as occludin protein levels transiently dropped. This drop is reflected in a concomitantly increased permeability for FD- 4 and HRP. Previous studies showed lower abundances of occludin mRNA and protein, claudin-3 protein, and increased lactulose permeability after weaning [50, 76]. Thus artificial rearing induced a similar response as seen after conventional weaning.

\section{Artificial rearing resulted in a redox imbalance}

Previously, we investigated the link between oxidative stress, intestinal integrity, and permeability in intestinal epithelial cells in vitro [12] and in vivo during normal 
suckling [21]. Vergauwen et al. [12] and others showed a redistribution of $\mathrm{TJ}$ proteins during times of imposing reactive species and could relate these responses to a compromised permeability [12, 77]. The current study demonstrated that transfer of piglets to a nursery resulted in oxidative stress.

Glutathione (GSH) is an important regulator of the redox status within intestinal epithelial cells [13]. The liver is the major site of GSH biosynthesis and exports GSH via the bile to the proximal SI [78]. Thus GSH originating from the liver supports mucosal GSH by decreasing lipid peroxidation and maintaining the GSSG/GSH redox homeostasis in the proximal intestine $[11,79,80]$. In our study, artificial rearing resulted in the liver in a decreased GSH content, an increased GSSG/ GSH ratio and MDA concentration. After this first phase, the redox parameters returned to their initial values. GSH-Px activity in the liver seemed unaffected during the transition period, while GSH-Px activity transiently dropped in the proximal and distal SI when piglets were introduced to a nursery. Previously, conventional weaning caused a drop in GSH-Px activity but GSH-Px activity increased afterwards as part of a feedback mechanism [31]. Our study shows that artificial rearing increases oxidative stress in the SI and as a result the GSH-Px activity increased and was higher than the activity seen in sow-reared piglets. Furthermore, LBW piglets showed a higher GSH-Px activity compared to their NBW littermates. It is clear that the antioxidant capacity of the liver helps protecting the proximal intestine by secreting GSH into the lumen of proximal SI $[78,79]$. This could explain the increased mucosal GSH concentration of the proximal SI and the concomitant massive decrease of the liver GSH concentration. On the other hand, a remarkable drop of the GSH concentration in the distal SI was observed from d3 until d5. Consequently, this resulted in a high concentration of MDA and GSSG, resulting in a higher GSSG/GSH ratio in the distal SI. Furthermore, the GSSG/GSH ratio increased systemically upon transfer to a nursery. Degroote et al. [31] already showed that conventional weaning increased the GSSG/GSH ratio.

Our research presents a window of opportunity for antioxidant supplementation to protect piglets from redox imbalance due to artificial rearing. NBW artificially reared piglets were more susceptible to redox imbalance and loss of intestinal integrity upon transferal to a nursery (from $\mathrm{d} 3$ to $\mathrm{d} 5$ ). Taken together, these findings favor the transfer of both LBW and NBW piglets to a nursery as a solution for LBW and supernumerary piglets. Further research is necessary to elucidate how these artificially reared LBW and NBW piglets will respond to the introduction to solid food.

\section{Conclusions}

In conclusion, we demonstrated that artificial rearing influences morphological and functional parameters in the small intestine, liver and blood in a way similar to what is seen after conventional weaning. Nevertheless, growth performance of artificially reared piglets was positively influenced. In addition, artificially reared piglets rapidly recovered from redox imbalances and restored intestinal permeability within a couple of days. Further research is needed to explore the possibility to supplement LBW and NBW piglets with antioxidants prior to initiating artificial rearing. Thus, artificial rearing is a valuable alternative to raise LBW or supernumerary piglets.

\section{Abbreviations \\ ELISA: Enzyme linked immunosorbent assay; FD-4: Fluorescein isothiocyanate dextran 4 kDa; GSH: Glutathione; GSH-Px: Glutathione peroxidase; \\ GSSG: Oxidized glutathione; HPLC: High performance liquid chromatography; HRP: Horseradish peroxidase; LBW: Low birth weight; MDA: Malondialdehyde; NBW: Normal birth weight; SI: Small intestine; TJs: Tight junctions}

\section{Acknowledgments}

We thank K. Huybrechts, G. Vrolix, K. Jennes, M. De Reys, S. Coolsaet, A. Ovyn and T. Van der Eecken for their technical assistance.

\section{Funding}

This work was supported by a grant from the government agency for Innovation by Science and Technology (IWT-LO 100856).

\section{Availability of data and materials \\ The datasets supporting the conclusions of this article are included within the article.}

\section{Authors' contributions}

Author contributions: CVG, JM and SDM concept and design of research; HV, JDG, WW, CVG and JM performed experiments; HV and JDG analyzed the data; HV and EF design and implementation of the statistical model; HV, JDG, CVG and JM interpreted the results of the experiments; HV and CVG prepared the figures; HV and CVG drafted manuscript; HV, JDG, CVG, JM, SDS, WW, CC, SVC and SP edited and revised the manuscript; CVG and JM approved the final version of the manuscript. All authors read and approved the final manuscript.

\section{Competing interests}

The authors declare that they have no competing interests.

\section{Consent for publication}

Not applicable.

\section{Ethics approval}

All husbandry and experimental procedures were approved by the Ethical Committee for Animal Testing (ECD) of the University of Antwerp (Belgium) (EC number: 2015-02) in accordance with the European Commission directive for the humane care and use of animals in research (2010/63/EU).

\section{Author details}

${ }^{1}$ Laboratory of Applied Veterinary Morphology, Department of Veterinary Sciences, Faculty of Biomedical, Pharmaceutical and Veterinary Sciences, University of Antwerp, Campus Drie Eiken, Universiteitsplein 1, D.U.015, 2610 Wilrijk, Belgium. ${ }^{2}$ Department of Applied Biosciences, Faculty of Bioscience Engineering, Ghent University, Ghent, Belgium. '²aboratory for Animal Nutrition and Animal Product Quality (LANUPRO), Department of Animal Production, Faculty of Bioscience Engineering, Ghent University, Melle, Belgium. ${ }^{4}$ StatUa Center for Statistics, University of Antwerp, Antwerp, Belgium. 
Received: 5 September 2016 Accepted: 16 March 2017 Published online: 08 April 2017

\section{References}

1. Lay Jr DC, Matteri RL, Carrol JA, Fangman TJ, Safranski TJ. Preweaning survival in swine. J Anim Sci. 2002;80(E. Suppl. 1):E74-86.

2. Tuchscherer M, Puppe B, Tuchscherer A, Tiemann U. Early identification of neonates at risk: traits of newborn piglets with respect to survival. Theriogenology. 2000;54(3):371-88. doi:10.1016/s0093-691x(00)00355-1.

3. Milligan BN, Dewey CE, de Grau AF. Neonatal-piglet weight variation and its relation to pre-weaning mortality and weight gain on commercial farms. Prev Vet Med. 2002:56(2):119-27.

4. Friel JK, Diehl-Jones B, Cockell KA, Chiu A, Rabanni R, Davies SS, et al. Evidence of oxidative stress in relation to feeding type during early life in premature infants. Pediatr Res. 2011;69(2):160-4. doi:10.1203/PDR. Ob013e3182042a07.

5. Ahola T, Levonen AL, Fellman V, Lapatto R. Thiol metabolism in preterm infants during the first week of life. Scand J Clin Lab Invest. 2004;64(7):649-58. doi:10.1080/00365510410002959

6. Rook D, Te Braake FW, Schierbeek H, Longini M, Buonocore G, Van Goudoever JB. Glutathione synthesis rates in early postnatal life. Pediatr Res. 2010;67(4):407-11. doi:10.1203/PDR.0b013e3181d22cf6.

7. Yin J, Ren W, Liu G, Duan J, Yang G, Wu L, et al. Birth oxidative stress and the development of an antioxidant system in newborn piglets. Free Radic Res. 2013:47(12):1027-35. doi:10.3109/10715762.2013.848277.

8. Tran H, Bundy JW, Li YS, Carney-Hinkle EE, Miller PS, Burkey TE. Effects of spray-dried porcine plasma on growth performance, immune response, total antioxidant capacity, and gut morphology of nursery pigs. J Anim Sci. 2014;92(10):4494-504. doi:10.2527/jas.2014-7620.

9. Michiels J, De Vos M, Missotten J, Ovyn A, De Smet S, Van Ginneken C. Maturation of digestive function is retarded and plasma antioxidant capacity lowered in fully weaned low birth weight piglets. $\mathrm{Br} J$ Nutr. 2013;109(1):65-75. doi:10.1017/s0007114512000670.

10. Krueger R, Derno M, Goers S, Metzler-Zebeli BU, Nuernberg G, Martens K, et al. Higher body fatness in intrauterine growth retarded juvenile pigs is associated with lower fat and higher carbohydrate oxidation during ad libitum and restricted feeding. Eur J Nutr. 2014;53(2):583-97. doi:10.1007/ s00394-013-0567-x

11. Aw TY. Intestinal glutathione: determinant of mucosal peroxide transport, metabolism, and oxidative susceptibility. Toxicol Appl Pharmacol. 2005:204(3):320-8. doi:10.1016/j.taap.2004.11.016.

12. Vergauwen $H$, Tambuyzer $B$, Jennes $K$, Degroote J, Wang W, De Smet $S$, et al. Trolox and ascorbic acid reduce direct and indirect oxidative stress in the IPEC-J2 cells, an in vitro model for the porcine gastrointestinal tract. PLoS One. 2015;10(3):e0120485. doi:10.1371/journal.pone.0120485.

13. Kelly FJ. Glutathione content of the small intestine: regulation and function. Br J Nutr. 1993;69(2):589-96.

14. Carrasco-Pozo C, Morales P, Gotteland M. Polyphenols Protect the Epithelial Barrier Function of Caco-2 Cells Exposed to Indomethacin through the Modulation of Occludin and Zonula Occludens-1 Expression. Journal of agricultural and food chemistry. 2013. doi:10.1021/jf400150p.

15. Bhattacharyya A, Chattopadhyay R, Mitra S, Crowe SE. Oxidative stress: an essential factor in the pathogenesis of gastrointestinal mucosal diseases. Physiol Rev. 2014;94(2):329-54. doi:10.1152/physrev.00040.2012.

16. Wang J, Chen L, Li D, Yin Y, Wang X, Li P, et al. Intrauterine growth restriction affects the proteomes of the small intestine, liver, and skeletal muscle in newborn pigs. J Nutr. 2008;138(1):60-6.

17. Wang $X$, Wu W, Lin G, Li D, Wu G, Wang J. Temporal proteomic analysis reveals continuous impairment of intestinal development in neonatal piglets with intrauterine growth restriction. J Proteome Res. 2010;9(2):924-35. doi:10.1021/pr900747d

18. Mickiewicz M, Zabielski R, Grenier B, Le Normand L, Savary G, Holst JJ, et al. Structural and functional development of small intestine in intrauterine growth retarded porcine offspring born to gilts fed diets with differing protein ratios throughout pregnancy. J Physiol Pharmacol. 2012;63(3):225-39.

19. Ferenc K, Pietrzak P, Godlewski MM, Piwowarski J, Kilianczyk R, Guilloteau P, et al. Intrauterine growth retarded piglet as a model for humans-studies on the perinatal development of the gut structure and function. Reprod Biol. 2014;14(1):51-60. doi:10.1016/j.repbio.2014.01.005.
20. D'Inca R, Gras-Le Guen C, Che L, Sangild PT, Le Huerou-Luron I. Intrauterine growth restriction delays feeding-induced gut adaptation in term newborn pigs. Neonatology. 2011;99(3):208-16. doi:10.1159/000314919.

21. Wang W, Degroote J, Van Ginneken C, Van Poucke M, Vergauwen $H_{\text {, }}$ Dam TM et al. Intrauterine growth restriction in neonatal piglets affects small intestinal mucosal permeability and mRNA expression of redoxsensitive genes. FASEB journal : official publication of the Federation of American Societies for Experimental Biology. 2015. doi:10.1096/fj.15-274779.

22. Huygelen V, De Vos M, Willemen S, Tambuyzer B, Casteleyn C, Knapen D, et al. Increased intestinal barrier function in the small intestine of formulafed neonatal piglets. J Anim Sci. 2012;90 Suppl 4:315-7. doi:10.2527/jas.53731.

23. Huygelen V, De Vos M, Willemen S, Fransen E, Casteleyn C, Van Cruchten S, et al. Age-related differences in mucosal barrier function and morphology of the small intestine in low and normal birth weight piglets. J Anim Sci. 2014;92(8):3398-406. doi:10.2527/jas.2014-7742.

24. Willemen S, Che L, De Vos M, Huygelen V, Tambuyzer B, Casteleyn C, et al. Perinatal growth restriction is not related to higher intestinal distribution and increased serum levels of 5-hydroxytryptamin in piglets. J Anim Sci. 2012;90 Suppl 4:305-7. doi:10.2527/jas.53730.

25. Ferrari CV, Sbardella PE, Bernardi ML, Coutinho ML, Vaz Jr IS, Wentz I, et al. Effect of birth weight and colostrum intake on mortality and performance of piglets after cross-fostering in sows of different parities. Prev Vet Med. 2014;114(3-4):259-66. doi:10.1016/j.prevetmed.2014.02.013.

26. De Vos M, Che L, Huygelen V, Willemen S, Michiels J, Van Cruchten S, et al. Nutritional interventions to prevent and rear low-birthweight piglets. J Anim Physiol Anim Nutr. 2014;98(4):609-19. doi:10.1111/jpn.12133.

27. Donovan TS, Dritz SS. Effect of split nursing on variation in pig growth from birth to weaning. J Am Vet Med Assoc. 2000;217(1):79-81.

28. De Vos M, Huygelen V, Willemen S, Fransen E, Casteleyn C, Van Cruchten S, et al. Artificial rearing of piglets: Effects on small intestinal morphology and digestion capacity. Livest Sci. 2014;159:165-73. doi:10.1016/j.livsci. 2013.11.012.

29. Wedig J, Christian MS, Hoberman A, Diener RM, Thomas-Wedig R. A study to develop methodology for feeding 24-hour-old neonatal swine for 3 weeks. Int J Toxicol. 2002;21(5):361-70. doi:10.1080/10915810290096577.

30. Fiorotto ML, Reeds PJ, Cunningham JJ, Pond WG. A semiautomatic device for feeding liquid milk-replacer diets to infant pigs. J Anim Sci. 1993;71(1):78-85

31. Degroote J, Michiels J, Claeys E, Ovyn A, De Smet S. Changes in the pig small intestinal mucosal glutathione kinetics after weaning. J Anim Sci. 2012;90 Suppl 4:359-61. doi:10.2527/jas.53809.

32. Zhu LH, Zhao KL, Chen $\mathrm{XL}$, Xu JX. Impact of weaning and an antioxidant blend on intestinal barrier function and antioxidant status in pigs. J Anim Sci. 2012;90(8):2581-9. doi:10.2527/jas.2012-4444.

33. Sauerwein $H$, Schmitz S, Hiss S. The acute phase protein haptoglobin and its relation to oxidative status in piglets undergoing weaning-induced stress. Redox Report. 2005;10(6):295-302. doi:10.1179/135100005x83725.

34. Klobasa F, Werhahn E, Butler JE. Composition of sow milk during lactation. J Anim Sci. 1987;64(5):1458-66.

35. Csapo J, Martin TG, Csapo-Kiss ZS, Hazas Z. Protein, fats, vitamin and mineral concentration in porcine colostrum and milk from parturition to 60 days. Int Dairy J. 1996;6(8-9):881-902.

36. Ontsouka CE, Bruckmaier RM, Blum JW. Fractionized milk composition during removal of colostrum and mature milk. J Dairy Sci. 2003;86(6):2005-11. doi:10.3168/jds.S0022-0302(03)73789-8.

37. Buesa RJ, Peshkov MV. How much formalin is enough to fix tissues? Ann Diagn Pathol. 2012;16(3):202-9. doi:10.1016/j.anndiagpath.2011.12.003.

38. McKie AT, Zammit PS, Naftalin RJ. Comparison of cattle and sheep colonic permeabilities to horseradish peroxidase and hamster scrapie prion protein in vitro. Gut. 1999:45(6):879-88.

39. Yoshida T. Determination of reduced and oxidized glutathione in erythrocytes by high-performance liquid chromatography with ultraviolet absorbance detection. J Chromatogr B Biomed Appl. 1996;678(2):157-64.

40. Reed DJ, Babson JR, Beatty PW, Brodie AE, Ellis WW, Potter DW. Highperformance liquid chromatography analysis of nanomole levels of glutathione, glutathione disulfide, and related thiols and disulfides. Anal Biochem. 1980;106(1):55-62.

41. Hernandez P, Zomeno L, Arino B, Blasco A. Antioxidant, lipolytic and proteolytic enzyme activities in pork meat from different genotypes. Meat Sci. 2004;66(3):525-9. doi:10.1016/s0309-1740(03)00155-4. 
42. Grotto D, Santa Maria LD, Boeira S, Valentini J, Charao MF, Moro AM, et al. Rapid quantification of malondialdehyde in plasma by high performance liquid chromatography-visible detection. J Pharm Biomed Anal. 2007;43(2):619-24. doi:10.1016/j.jpba.2006.07.030.

43. Aguinaga MA, Gomez-Carballar F, Nieto R, Aguilera JF. Production and composition of Iberian sow's milk and use of milk nutrients by the suckling Iberian piglet. Animal. 2011;5(9):1390-7. doi:10.1017/s1751731111000474

44. Han F, Hu L, Xuan Y, Ding X, Luo Y, Bai S, et al. Effects of high nutrient intake on the growth performance, intestinal morphology and immune function of neonatal intra-uterine growth-retarded pigs. Br J Nutr. 2013;110(10):1819-27. doi:10.1017/s0007114513001232.

45. Ermer PM, Miller PS, Lewis AJ. Diet preference and meal patterns of weanling pigs offered diets containing either spray-dried porcine plasma or dried skim milk. J Anim Sci. 1994;72(6):1548-54.

46. Caspary WF. Physiology and pathophysiology of intestinal absorption. Am J Clin Nutr. 1992;55(1 Suppl):299s-308s.

47. Egberts HJ, de Groot EC, van Dijk JE, Vellenga L, Mouwen JM. Tight junctional structure and permeability of porcine jejunum after enterotoxic Escherichia coli infection. Res Vet Sci. 1993;55(1):10-4.

48. Van Ginneken C, Van Meir F, Weyns A. Stereologic characteristics of pig small intestine during normal development. Dig Dis Sci. 2002;47(4):868-78.

49. Cera KR, Mahan DC, Reinhart GA. Effect of weaning, week postweaning and diet composition on pancreatic and small intestinal luminal lipase response in young swine. Journal of animal science. 1990;68(2). doi:10.2527/1990. $682384 x$.

50. Wang J, Zeng L, Tan B, Li G, Huang B, Xiong X, et al. Developmental changes in intercellular junctions and Kv channels in the intestine of piglets during the suckling and post-weaning periods. J Anim Sci Biotechnol. 2016;7:4. doi:10.1186/s40104-016-0063-2.

51. Huygelen V, De Vos M, Prims S, Vergauwen H, Fransen E, Casteleyn C, et al. Birth weight has no influence on the morphology, digestive capacity and motility of the small intestine in suckling pigs. Livest Sci. 2015;182:129-36. http://dx.doi.org/doi:10.1016/J.LIVSCI.2015.11.003.

52. Midtvedt AC, Carlstedt-Duke B, Midtvedt T. Establishment of a mucindegrading intestinal microflora during the first two years of human life. J Pediatr Gastroenterol Nutr. 1994;18(3):321-6.

53. Phillips TE. Both crypt and villus intestinal goblet cells secrete mucin in response to cholinergic stimulation. Am J Physiol. 1992;262(2 Pt 1):G327-31.

54. Funderburke DW, Seerley RW. The effects of postweaning stressors on pig weight change, blood, liver and digestive tract characteristics. J Anim Sci. 1990;68(1):155-62.

55. van Beers-Schreurs HM, Nabuurs MJ, Vellenga L, Kalsbeek-van der Valk HJ, Wensing T, Breukink HJ. Weaning and the weanling diet influence the villous height and crypt depth in the small intestine of pigs and alter the concentrations of short-chain fatty acids in the large intestine and blood. J Nutr. 1998;128(6):947-53.

56. Kelly D, Smyth JA, McCracken KJ. Digestive development of the earlyweaned pig. 1. Effect of continuous nutrient supply on the development of the digestive tract and on changes in digestive enzyme activity during the first week post-weaning. Br J Nutr. 1991;65(2):169-80.

57. Kelly D, Smyth JA, McCracken KJ. Digestive development of the earlyweaned pig. 2. Effect of level of food intake on digestive enzyme activity during the immediate post-weaning period. Br J Nutr. 1991:65(2):181-8.

58. Spreeuwenberg MA, Verdonk JM, Gaskins HR, Verstegen MW. Small intestine epithelial barrier function is compromised in pigs with low feed intake at weaning. J Nutr. 2001;131(5):1520-7.

59. Hedemann MS, Hojsgaard S, Jensen BB. Small intestinal morphology and activity of intestinal peptidases in piglets around weaning. J Anim Physiol Anim Nutr. 2003;87(1-2):32-41.

60. Pierce JL, Cromwell GL, Lindemann MD, Russell LE, Weaver EM. Effects of spray-dried animal plasma and immunoglobulins on performance of early weaned pigs. J Anim Sci. 2005:83(12):2876-85.

61. Touchette KJ, Allee GL, Matteri RL, Dyer CJ, Carroll JA. Effect of spraydried plasma and Escherichia coli on intestinal morphology and the hypothalamic-pituitary-adrenal (HPA) axis of the weaned pig. J Anim Sci. 1999;77(Supplement 1):56

62. Jiang $R$, Chang $X$, Stoll B, Fan MZ, Arthington J, Weaver E, et al. Dietary plasma protein reduces small intestinal growth and lamina propria cell density in early weaned pigs. J Nutr. 2000;130(1):21-6.

63. van Dijk AJ, Niewold TA, Margry RJ, van den Hoven SG, Nabuurs MJ, Stockhofe-Zurwieden $\mathrm{N}$, et al. Small intestinal morphology in weaned piglets fed a diet containing spray-dried porcine plasma. Res Vet Sci. 2001;71(1):17-22. doi:10.1053/rvsc.2001.0478.

64. Ramanan D, Cadwell K. Intrinsic Defense Mechanisms of the Intestinal Epithelium. Cell host \& microbe. 2016. doi:10.1016/j.chom.2016.03.003.

65. Boudry G. The Ussing chamber technique to evaluate alternatives to in-feed antibiotics for young pigs. Animal Res. 2005:54:219-30.

66. Schneeberger EE, Lynch RD. The tight junction: a multifunctional complex. Am J Physiol Cell Physiol. 2004;286(6):C1213-28. doi:10.1152/ajpcell.00558.2003.

67. Lu Z, Ding L, Lu Q, Chen Y-H. Claudins in intestines: distribution and functional significance in health and diseases. Tissue Barriers. 2013;1(3):e24978. doi:10.4161/tisb.24978.

68. Anderson JM, Van Itallie CM, Fanning AS. Setting up a selective barrier at the apical junction complex. Curr Opin Cell Biol. 2004;16(2):140-5. doi:10.1016/j.ceb. 2004.01.005

69. Furuse M, Tsukita S. Claudins in occluding junctions of humans and flies. Trends Cell Biol. 2006;16(4):181-8. doi:10.1016/j.tcb.2006.02.006.

70. Yu AS, McCarthy KM, Francis SA, McCormack JM, Lai J, Rogers RA, et al. Knockdown of occludin expression leads to diverse phenotypic alterations in epithelial cells. Am J Physiol Cell Physiol. 2005;288(6):C1231-41. doi:10.1152/ajpcell.00581.2004.

71. Raleigh DR, Boe DM, Yu D, Weber CR, Marchiando AM, Bradford EM, et al. Occludin S408 phosphorylation regulates tight junction protein interactions and barrier function. J Cell Biol. 2011;193(3):565-82. doi:10.1083/jcb. 201010065.

72. Patel RM, Myers LS, Kurundkar AR, Maheshwari A, Nusrat A, Lin PW. Probiotic bacteria induce maturation of intestinal claudin 3 expression and barrier function. Am J Pathol. 2012;180(2):626-35. doi:10.1016/j. ajpath.2011.10.025.

73. Holmes JL, Van Itallie CM, Rasmussen JE, Anderson JM. Claudin profiling in the mouse during postnatal intestinal development and along the gastrointestinal tract reveals complex expression patterns. Gene Expression Patterns. 2006;6(6):581-8. doi:10.1016/j.modgep.2005.12.001.

74. Mackie Rl, Sghir A, Gaskins HR. Developmental microbial ecology of the neonatal gastrointestinal tract. Am J Clin Nutr. 1999;69(5):1035s-45s.

75. Milatz S, Krug SM, Rosenthal R, Gunzel D, Muller D, Schulzke JD, et al. Claudin-3 acts as a sealing component of the tight junction for ions of either charge and uncharged solutes. Biochim Biophys Acta. 2010;1798(11):2048-57. doi:10.1016/j. bbamem.2010.07.014

76. Wang H, Zhang C, Wu G, Sun Y, Wang B, He B, et al. Glutamine enhances tight junction protein expression and modulates corticotropin-releasing factor signaling in the jejunum of weanling piglets. J Nutr. 2015;145(1):25-31. doi:10.3945/jn.114.202515.

77. Fukui A, Naito Y, Handa O, Kugai M, Tsuji T, Yoriki H et al. Acetyl salicylic acid induces damage to intestinal epithelial cells by oxidation-related modifications of ZO-1. American journal of physiology Gastrointestinal and liver physiology. 2012. doi:10.1152/ajpgi.00236.2012.

78. Lee TK, Li L, Ballatori N. Hepatic glutathione and glutathione S-conjugate transport mechanisms. Yale J Biol Med. 1997:70(4):287-300.

79. Aw TY. Biliary glutathione promotes the mucosal metabolism of luminal peroxidized lipids by rat small intestine in vivo. J Clin Investig. 1994;94(3):1218-25.

80. Ballatori N, Truong AT. Relation between biliary glutathione excretion and bile acid-independent bile flow. Am J Physiol. 1989;256(1 Pt 1):G22-30.

\section{Submit your next manuscript to BioMed Central and we will help you at every step:}

- We accept pre-submission inquiries

- Our selector tool helps you to find the most relevant journal

- We provide round the clock customer support

- Convenient online submission

- Thorough peer review

- Inclusion in PubMed and all major indexing services

- Maximum visibility for your research

Submit your manuscript at www.biomedcentral.com/submit 